\begin{tabular}{|c|}
\hline 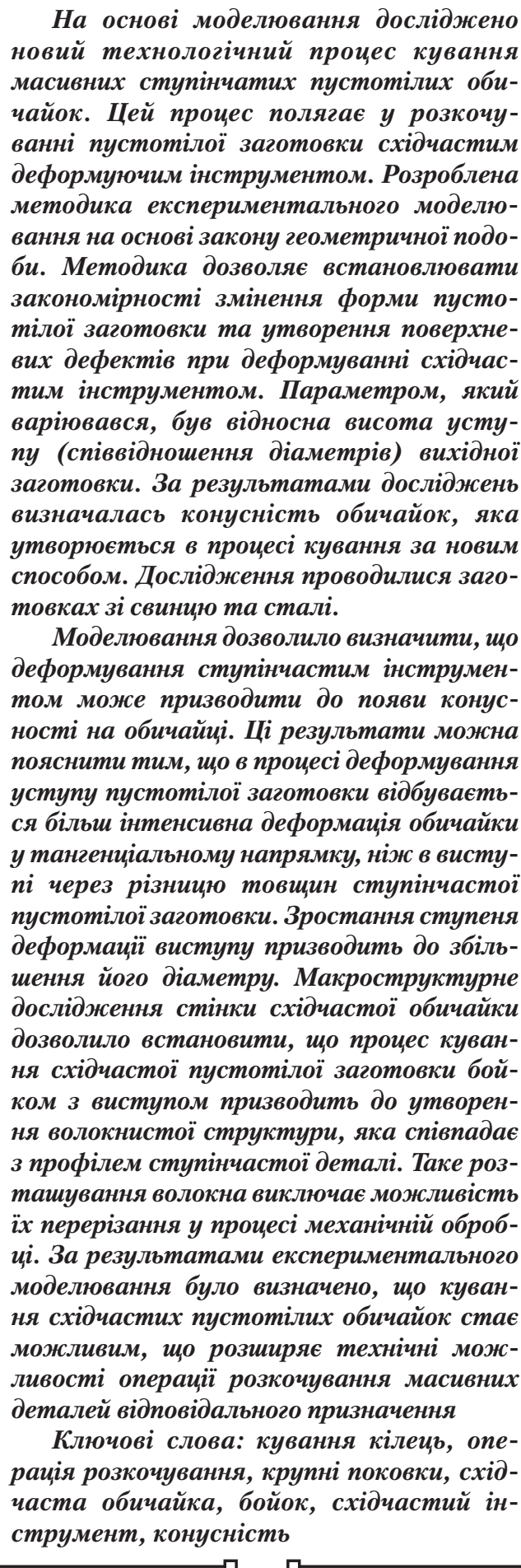 \\
\hline
\end{tabular}

Received date 30.09.2019

Accepted date 06.11.2019

Published date 10.12.2019
UDC 621.736 .2

DOI: $10.15587 / 1729-4061.2019 .183663$

\section{MODELING AND IMPROVEMENT OF SADDLING A STEPPED HOLLOW WORKPIECE WITH A PROFILED TOOL}

\author{
O. Markov \\ Doctor of Technical Sciences, Professor, Head of Department* \\ E-mail: oleg.markov.omd@gmail.com \\ M. Kosilov \\ Chief Specialist \\ Department of Economics \\ Donetsk Regional State Administration \\ Oleksy Tykhoho str., 6, Kramatorsk, Ukraine, 84306 \\ V. Panov \\ Head of Department \\ Department of Forging \\ PJSC «Energomashspetsstal» \\ Oleksy Tykhoho str., 1, Kramatorsk, Ukraine, 84305 \\ V. Ku k h a r \\ Doctor of Technical Sciences, Professor, Head of Department \\ Department of Metal Forming \\ Pryazovskyi State Technical University \\ Universytetska str., 7, Mariupol, Ukraine, 87555
}

S. Karnaukh

PhD, Associate Professor, Head of Department Department of Basics of Designing a Machine**

N. Ragulin a

$\mathrm{PhD}$, Associate Professor Department of Enterprise Economics**

P. Bochanov

Senior Lecturer*

P. R i z a k

Head Master

PJSC «Novokramatorsky Mashinostroitelny Zavod» Ordzhonikidze str., 1, Kramatorsk, Ukraine, 84305

*Department of Computational Design and Modeling Processes and Machines**

**Donbass State Engineering Academy

Akademichna str., 72, Kramatorsk, Ukraine, 84313

\section{Introduction}

The priority area of machine building engineering is the development of energy-saving processes for the manufacture of articles for responsible purposes used at power plants. This is due to the advancement and introduction of new knowledge-intensive technologies that improve the quality
Copyright (C) 2019, O. Markov, M. Kosilov, V. Panov, V. Kukhar,

S. Karnaukh, N. Ragulina, P. Bochanov, P. Rizak This is an open access article under the CC BY license (http://creativecommons.org/licenses/by/4.0) 
productivity, savings of material and energy resources. Solving these problems is contributed to by the introduction of progressive technological processes in the industry to forge rings [1]. The optimality criteria in this case are the high quality and accepTable cost of parts for responsible purposes. Development of scientific foundations to improve quality and reduce costs in the manufacture of large forgings for responsible purposes necessitates undertaking a specialized research to devise new, as well as improve existing, technological processes of forging and forging tools. This requires an integrated approach that takes into consideration the complex chain of the entire technological sequence of ring production, from ingot manufacturing to their further forging to machining. It is a relevant scientific and practical task in the processes of forging large forgings is the manufacture of blanks with a stepped profile, which repeats the geometry of the part. That would make it possible not to cut the internal fibrous structure of the blank and to improve a metal utilization factor. To solve this issue, it is necessary to undertake a research into a new technique of saddling stepped forgings based on modeling that involves workpieces made of lead and steel.

\section{Literature review and problem statement}

Optimizing the technological processes of making large blanks implies the elimination or replacement of inefficient, energy-intensive operations with those that do not increase costs and warrant at the same time the predefined quality [2]. One such operation is saddling. It is possible to eliminate the saddling operation by using new ingots $[3,4]$. As stated in paper [5], in order to improve the quality of forgings for responsible purposes, to develop new and promising power plants with enhanced capacity, a technology was devised for the production of large-sized rings. Work [6] assesses the technical advantages of producing large-sized forgings for responsible purposes. However, the cited studies [2-6] do not describe the technological modes and recommendations for rings forging.

Article [7] reports an improved technology for casting hollow ingots in order to save metal in the manufacture of hollow parts. The authors' modeling of the process of pouring and crystallization of a hollow ingot indicated a decrease in segregation and a lower depth of the shrinkage cavity in comparison with conventional ingots. However, article [7] does not examine the segregation in the obtained ingots and there are no data on the mechanical properties of the received rings.

Study [8] developed a new technology for casting a 200-ton hollow ingot for the manufacture of rings. The resulting forging had high indicators of mechanical properties. However, study [8] does not specify the sequence of technological forging operations or how this affected the resulting mechanical properties of the forging.

The use of a hollow ingot as a semi-finished product for the production of hollow forgings is not only cost-effective, but ensures improvement in the forging quality. The mechanical properties of forgings become more uniform in all directions, while the size of macroliquations is much lower than that when using a regular ingot [9]. However, the cited paper gives no results from metallographic studies for the forgings obtained.

Work [10] considered different empirical ratios of the geometric sizes of rings during the manufacture of a ring by using a conventional technology of forging from a standard ingot. These recommendations were proposed for the proper control over a shape in the process of forging rings on a man- drel. When obtaining a thin-walled ring, these recommendations improve utilization rate of a material compared to the method of traditional ring saddling. The cited work does not investigate the impact of deformation technique on quality indicators, as well as gives no information on the conditions of the experiment and the size of the forgings received.

Two rings were forged to make a reactor. One had an outside flange and the other had an inner flange. A feature of the technique is that the rings with flanges were forged using a stepped upper die [11-13]. However, the cited papers give no recommendations on the ratio of a blank's dimensions, which was used for saddling, and the parameters of the tool's working surface.

A technique for making a large-sized forging for a reactor unit's ring [14] implied forging the ring and flange with further welding. That led to an increase in the number of welds, which under radiation conditions lead to premature corrosion. It would be useful to consider in the work a technique for making a solid-forged forging with a flange.

Papers [15-17] consider the process of forming a conical ring with cylindrical sections. The forging process consists of conventional operations, but, during last transitions, a special rig is used to forge a cylindrical section of the forging. However, the cited papers lack data on forging modes for the predefined forging.

Manufacture of forgings with a collar is accompanied by defects at the end of the ledge or at the inner surface from the side of the ledge [18]. A rational way to solve this issue is to model the saddling process by a finite-element method (FEM). Paper [19] applies a FEM to examine the factors that influence the occurrence of defects during the manufacture of hollow blanks. But the cited paper does not specify how the chemical composition of a material affects the quality of articles. The presence of defects in the surface layers of a blank could cause further cracks during forging.

Authors of work [20] optimized the process of forging large forgings based on FEM, which implies studying the effect of tool shape on a change in the shape of a blank during forging. Such a concept, whose effectiveness was demonstrated only using a specific example, does not combine the possibilities of virtual analysis, practical observations, and could only be used to evaluate a specific forging process.

Papers [21-24] investigated closing internal discontinuities when broaching and reducing hot ingots. The established technological parameters were feed and reduction at deformation. Study [25] applied a FEM to compare broaching techniques when using the flat and combined dies. It was established that when using the combined dies, deformations are more concentrated in the central zone of a forging, by $15 \%$. However, the cited papers do not give data on the development of internal defects at broaching and saddling.

Study [26] tested a possibility of saddling large-sized rings. The authors determined the stresses that occur in the deforming tool and the forging. Work [27] carried out computer simulation, a 1:30 scale lead test, a 1:5 prototype test, and a 1:1 scale layout test, to improve the ring forging process. However, the cited papers report results from forging the forgings with a simple geometry, while the forging of complex-profile rings was not considered.

Analysis of scientific publications [14-27] has revealed that the task on increasing the utilization factor of a material during machining and on improving the mechanical characteristics of a material in the manufacture of stepped rings has not been fully resolved up to now. The steps of rings are as- 
signed with a significant technological margin for machining. This leads to excessive consumption of the material, as well as to cutting the internal fibrous structure. Therefore, it is necessary to improve the forging technique for large stepped rings.

\section{The aim and objectives of the study}

The aim of this study is to improve the quality and utilization rate of a material by modeling and improving the technological process of forging rings with a flange.

To accomplish the aim, the following tasks have been set:

- to devise a technique for modeling the process of saddling rings with a flange;

- to conduct an experimental simulation of the process of saddling a ring with a flange using lead blanks and, based on the results from simulation, to determine the dependences of change in the shape of a forging on the different ratios of geometric sizes of the blank and the technological modes of forging;

- to perform metallographic studies of the parts obtained in line with a new technique using steel models to assess the impact of the new deformation technique on the quality of forgings.

\section{A procedure for modeling the saddling of rings with a flange}

Lead was selected as a material to model the saddling under laboratory conditions [28] as this metal has a low recrystallization temperature $\left(\approx 20^{\circ} \mathrm{C}\right)$. Modeling that employs lead blanks does not contradict the position of the similarity theory [29]. To change the mechanical characteristics of the model material, antimony was added to lead (up to $5 \%$ ). The set-up for experimental modeling is shown in Fig. 1. During the forging process, the magnitude of sample reduction was varied. For the study, hollow models with a scale of 1:50 were made. A hole in the blank had a taper (1:100). This taper is obtained during a preliminary operation of broaching on a conical mandrel. To simplify calculations and designations, it was decided during the study to introduce a parameter for the average hole diameter $\left(d_{c p}\right)$. The saddling was carried out at a hydraulic press with an effort of $0.1 \mathrm{MN}$, the deformation rate was $5 \mathrm{~mm} / \mathrm{s}$. For a macrostructural study, the saddling of models made of steel was performed.

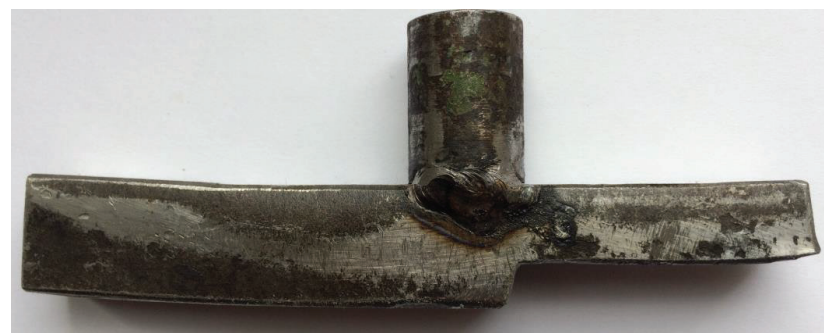

Fig. 1. Profiled die

Steel hollow blanks were heated, before deformation, in the furnace to a temperature of $1,050^{\circ} \mathrm{C}$ at aging of 25 minutes. A single reduction over one rotation of the blank was $0.5 \mathrm{~mm}$.

Calculating the process of saddling forgings with a variable thickness of the wall presents a complex research task, predetermined by the influence of a significant number of factors on a given process. Therefore, we planned the experiment to obtain information that describes a change in the size of a blank at deformation. A full-factor experiment (FFE), the type of FFE $3^{2}$, was chosen as a plan. The result of planning was the established center of the plan and the variation levels. The center of the plan for the relative diameter of the ledge is 2.4 , at a variation level of 0.1 . For the degree of deformation, the center of the plan was 0.2 and the step was 0.1 . Under these parameters, it is possible to maximally cover the size range of blanks, which can be made with ledges. The rate of deformation and a friction factor would not change during the experiment. Thus, we identified two main factors influencing the process of saddling the rings with a flange - relative diameter of the protrusion of a blank and the degree of deformation (Table 1), as well as the parameters for their variation.

Table 1

Main factors and levels of their variation for plan FFE $3^{2}$

\begin{tabular}{|l|c|c|}
\hline \multirow{2}{*}{$\begin{array}{c}\text { Factors and intervals of } \\
\text { their variation }\end{array}$} & $x_{1}$ & $x_{2}$ \\
\cline { 2 - 3 } & $D_{B} / d_{c p}$ & $\varepsilon$ \\
\hline Variation interval $\Delta x_{i}$ & 0.1 & 0.1 \\
\hline Lower level $x_{i}=-1$ & 2.5 & 0.1 \\
\hline Medium level $x_{i}=0$ & 2.4 & 0.2 \\
\hline Upper level $x_{i}=+1$ & 2.3 & 0.3 \\
\hline
\end{tabular}

\section{Results of modeling the saddling of a ring with a flange}

\section{1. Shape changes}

We studied two forging strategies for the size of the blanks with ratio $D_{y} / d_{c p}=1.85$ ( $D_{y}$ is the outer diameter of the ledge). A first one implies that a flange deforms in the beginning of saddling (Fig. 2, $a$ ), a second one implies the simultaneous reduction of the flange and ledge (Fig. 2, $b$ ). Upon reducing the blanks, the lowest taper is obtained for the ring, which was deformed with a ledge diameter $D_{B} / d_{c p}$ equal to 2.5 ( $D_{B}$ is the outer diameter of the protrusion), and the largest is for $D_{B} / d_{c p}=2.3$ (Fig. 3 ).

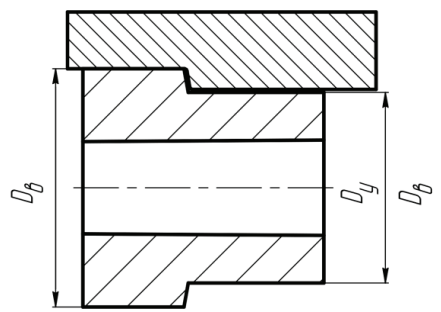

a

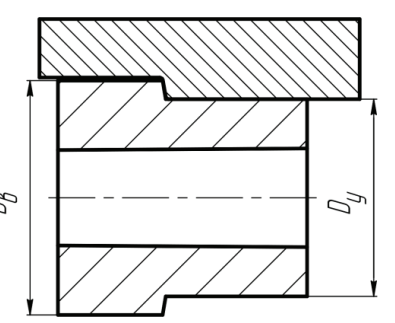

$b$
Fig. 2. Two forging strategies for rings with a flange: $a$ - deformation begins from a protrusion; $b$ - deformation begins from a protrusion and a ledge

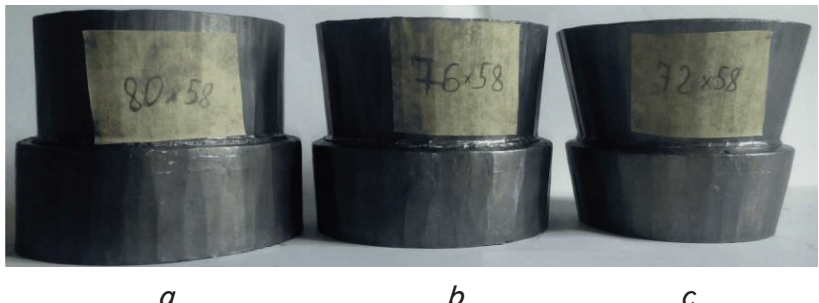

Fig. 3. Rings after forging $\left(D_{y} / d_{c p}=1.85\right)$ : $a-D_{B} / d_{c p}=2.5 ; b-D_{B} / d_{c p}=2.4 ; c-D_{B} / d_{c p}=2.3$ 
For a stepped sample with $D_{B} / d_{c p}$ equal to 2.5 the degree of reduction of the protrusion is larger than that of a ledge (Fig. 4, $a$ ). This is due to the difference between the height of the step on the blank and the die. As a result, the ledge is not reduced at the initial stage. At further reduction, both the protrusion and ledge are reduced.

For a stepped sample with $D_{B} / d_{c p}$ equal to 2.4 the deformation of the flange is larger than that of the ledge at the initial forging point (Fig. 4, b). The difference between the diameters in the flange and the ledge decreases when the ledge begins to deform. For a stepped sample with $D_{B} / d_{c p}=2.3$ (Fig. 4, $c$ ) the flange and ledge are forged at the same time. In this case, the diameter from the ledge side increases faster than that of the protrusion.

An increase in the reduction degree of the protrusion $\left(\varepsilon_{p}\right)$ leads to an increase in the diameter of the hole (Fig. 5). The results from modeling indicate that at the diameters of flanges equal to 2.5 and 2.4 and the reduction of the flange less than 0.1 , the difference in the diameters of the flange and ledge increases. In this case, the internal diameter of the protrusion is increased $d_{n . p} / L_{n}\left(d_{n . p}\right.$ is the diameter of the forging hole on the side of the protrusion; $L_{n}$ is the length of the forging). For a stepped sample with $D_{B} / d_{c p}=2.4$, the reduction by $30 \%$ is followed by crossing the lines of the chart $d_{n . l} / L_{n}$ and $d_{n . p} / L_{n}\left(d_{n . l}\right.$ is the diameter of the forging hole on the side of the ledge), that is the taper is minimal under these conditions.

For the ring with $D_{B} / d_{c p}=2.3$, the internal diameter $d_{n . l} / L_{n}$ increases more intensively at the initial stage of forging than $d_{n . p} / L_{n}$, but the curves do not intersect indicating the emergence of taper. Intensive growth $d_{n . l} / L_{n}$ in all cases is characterized by a significant reduction of the ledge. Analysis of data on change in the magnitude of taper for forgings with $D_{y} / d_{c p}=1.85$ (Fig. $6, a$ ) has revealed that the increased reduction degree of a flange leads to that taper changes differently. For $D_{B} / d_{c p}=2.5$, taper grows, which is due to the deformation of the flange. Then the taper does not change, which is explained by an even increase in the internal diameter of the ledge and flange. Further reduction of taper is associated with an increase in the internal diameter of the ledge. The difference between the total degrees of deformation of the ledge and flange is reduced, which reduces the taper of the stepped sample.

With the increasing degree of reduction $(\varepsilon)$, the ratios of the internal diameters of the flange and ledge decrease (Fig. 6, $b$ ). At the same time, the diameters of the blanks increase for cases when $D_{B} / d_{c p}$ become equal to 2.5 and 2.4. The ratio of diameters of the flange and ledge for $D_{B} / d_{c p}=2.5$ is approaching unity, the result being a decrease in the taper.
Curve 2 is lower than unity, indicating a change in the direction of taper during deformation. Curve 3 does not exceed unity, which corresponds to the constant formation of ring taper.
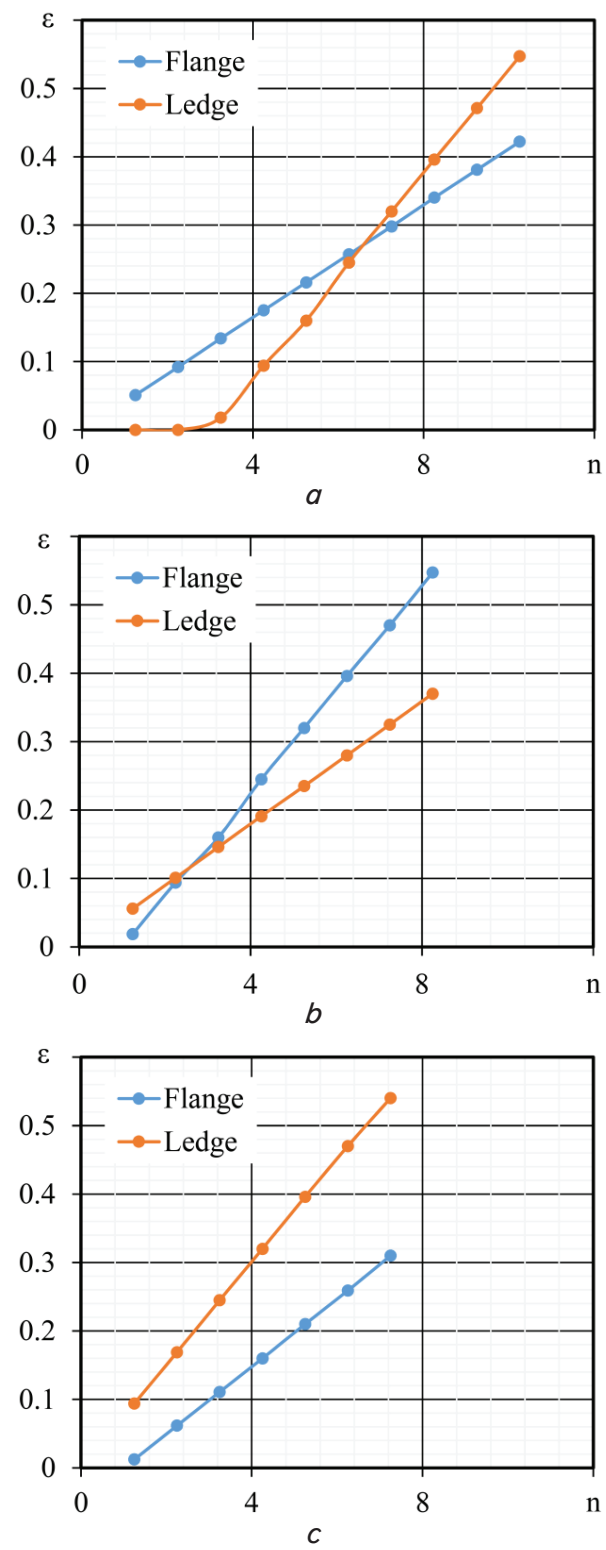

Fig. 4. Patterns of change in the degree of reduction of the flange and ledge $(\varepsilon)$ on the number of runs $\left(D_{y} / d_{c p}=1.85\right)$ : $a-D_{B} / d_{c p}=2.5 ; b-D_{B} / d_{c p}=2.4 ; c-D_{B} / d_{c p}=2.3$

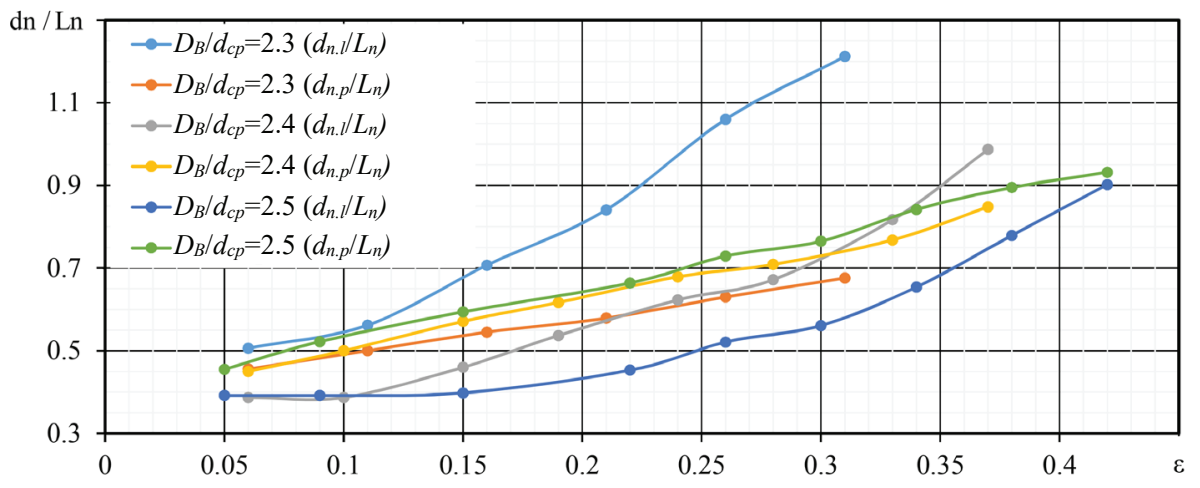

Fig. 5. Dependence of the ring internal diameter $d_{n} / L_{n}$ on the reduction degree $\varepsilon_{p}\left(D_{y} / d_{c p}=1.85\right)$ 

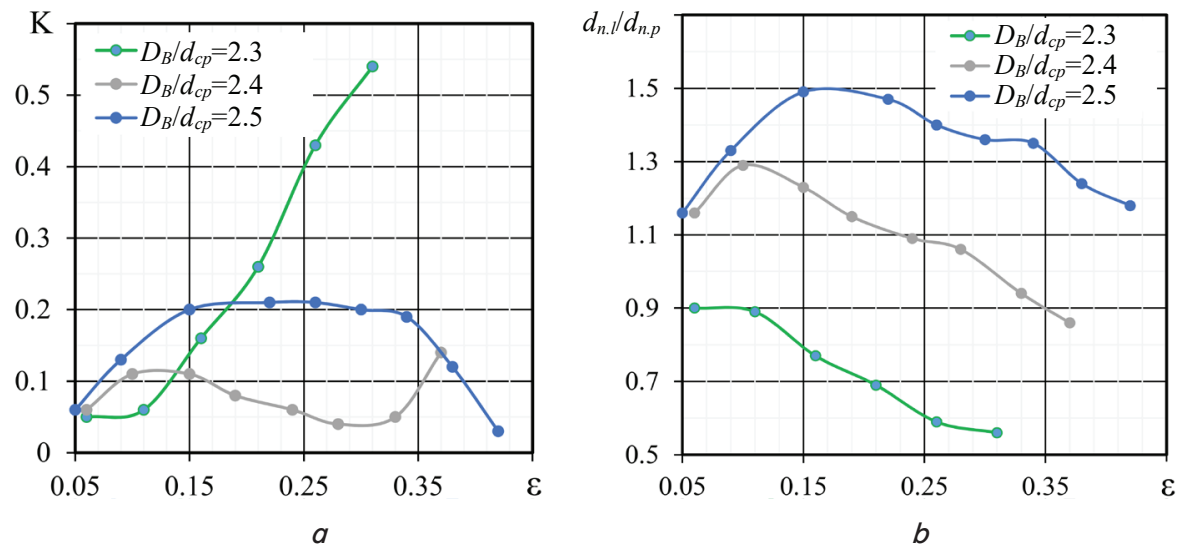

Fig. 6 . Change in the shape of a forging depending on the degree of reduction: $a$ - change in taper; $b$ - change in internal diameters of ledge and flange

\section{2. Modeling on steel samples}

Initial information about the development of the metal structure after deformation and detection of the prevailing flow of metal can be obtained following the analysis of the macrostructure of a forging. In this case, it is necessary to establish a change in the structure of the metal at the site of wall change. Macrostructural analysis of the ring (Fig. 7, $a$ ) obtained under the new forging strategy has confirmed that the article has a directed texture whose fibers repeat the profile of the received ring (Fig. $7, b$ ).

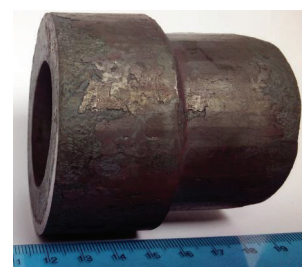

a

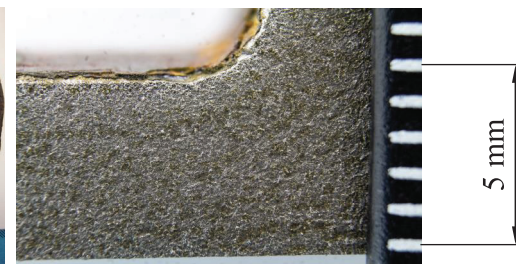

$b$
Fig. 7. Results of the experiment on steel models: $a$ - ring with a flange after forging; $b$ - macrostructure in a ledge

It has been established that the developed forging technique deforms the metal in a ledge more intensively (Fig. 7, $b$ ). The arrangement of fiber corresponds to the contours of the ring. This would reduce the number of fibers that are cut at machining.

\section{Discussion of results from a new technique of forging rings with a ledge}

Based on modeling using steel and lead samples, we have established patterns of change in the shape of the ring when forging with a profiled die (Fig. 4-6). As a result, we have identified the rational reduction regimes for forging stepped rings and defined the benefits of the proposed technique over the conventional forging technique:

- the use of a blank with a ledge and a profiled die has made it possible to obtain rings with a flange. As a result, it has become possible to reduce the magnitude of technological margin, which enabled a decrease in the consumption of metal by $6 \ldots 10 \%$, which can be seen from the shape of the forging shown in Fig. 7, $a$ (the difference of masses between a smooth ring with a protrusion and a ring with a ledge is not given in this work as the calculation is elementary);

- forging with a profiled die has made it possible to receive an article that repeats the shape and size of a part, the result being a decrease in the ledge machining time (Fig. 7, $a$ );

- a given process could also be used to produce stepped taper-shaped rings, as shown in work [29].

The disadvantages of the devised forging process include:

- difference in the reduction of the protrusion and ledge of a stepped ring could lead to a slight anisotropy of mechanical properties in these zones;

- the process of forming a taper of the ring makes it a little more difficult to rotate the stepped ring on a mandrel.

Technical application of the established results is the development of a new technological process for forging rings with flanges. Earlier studies [14-27] have examined the technological processes of forging cone-like rings. The current work reveals patterns in the production by forging of conical and cylindrical rings with flanges.

It should be noted that the work did not investigate the processes of obtaining such cone rings by saddling, which have an extension on the side of the protrusion. In this regard, further modeling of the processes of forging stepped rings should be directed towards establishing patterns that would make it possible to identify the effect of the shape and size of a stepped workpiece and the profile of the deforming stepped die. That would enable an increase in the diameter of a ring from the side of a protrusion at deformation.

\section{Conclusions}

1. We have devised a procedure for modeling the process of saddling rings with a flange using lead and steel samples, which has made it possible to establish a change in the shape of a stepped workpiece in the process of saddling with a profiled die. Its feature is a possibility to study a change in the shape of stepped blanks and to assess the basic quality indicators of the forgings obtained in line with the new technology. The devised procedure has allowed us to conduct a study into the process of saddling large forgings using reduced models, which decreased the cost of conducting experiments.

2. Experimental modeling using lead and steel samples has established that the stepped samples with a flange at $D_{B} / d_{c p}=2.4 \ldots 2.5$ demonstrate an increase in taper at forging. At the same-time reduction of the flange and ledge, there is 
the formation of taper. Increased reduction leads to a change in the direction of taper. This occurs as a result of an intense deformation in the ledge, which leads to an increase in diameter. It was determined that the main parameter of blanks to control the flow of metal at saddling is the size of the ledge. Relative height of the ledge in the 0.45 range ensures obtaining a ring with minimal taper.
3. Our analysis of the macrostructure of a stepped ring has revealed that forging a blank with a variable thickness of the wall with a profile die ensures the location of fiber along the shape of an article, which would eliminate the cutting of fiber at machining (similar to saddling a ring without a protrusion) and could lead to the increased fatigue of a part.

\section{References}

1. Markov, O., Gerasimenko, O., Khvashchynskyi, A., Zhytnikov, R., Puzyr, R. (2019). Modeling the techological process of pipe forging without a mandrel. Eastern-European Journal of Enterprise Technologies, 3 (1 (99)), 42-48. doi: https://doi.org/10.15587/ 1729-4061.2019.167077

2. Kukhar, V., Balalayeva, E., Hurkovska, S., Sahirov, Y., Markov, O., Prysiazhnyi, A., Anishchenko, O. (2019). The Selection of Options for Closed-Die Forging of Complex Parts Using Computer Simulation by the Criteria of Material Savings and Minimum Forging Force. Intelligent Communication, Control and Devices, 325-331. doi: https://doi.org/10.1007/978-981-13-8618-3 35

3. Markov, O. E., Gerasimenko, O. V., Shapoval, A. A., Abdulov, O. R., Zhytnikov, R. U. (2019). Computerized simulation of shortened ingots with a controlled crystallization for manufacturing of high-quality forgings. The International Journal of Advanced Manufacturing Technology, 103 (5-8), 3057-3065. doi: https://doi.org/10.1007/s00170-019-03749-4

4. Markov, O. E., Gerasimenko, O. V., Kukhar, V. V., Abdulov, O. R., Ragulina, N. V. (2019). Computational and experimental modeling of new forging ingots with a directional solidification: the relative heights of 1.1. Journal of the Brazilian Society of Mechanical Sciences and Engineering, 41 (8). doi: https://doi.org/10.1007/s40430-019-1810-z

5. Markov, O., Gerasimenko, O., Aliieva, L., Shapoval, A., Kosilov, M. (2019). Development of a new process for expanding stepped tapered rings. Eastern-European Journal of Enterprise Technologies, 2 (1 (98)), 39-46. doi: https://doi.org/10.15587/ 1729-4061.2019.160395

6. Markov, O., Zlygoriev, V., Gerasimenko, O., Hrudkina, N., Shevtsov, S. (2018). Improving the quality of forgings based on upsetting the workpieces with concave facets. Eastern-European Journal of Enterprise Technologies, 5 (1 (95)), 16-24. doi: https://doi.org/ 10.15587/1729-4061.2018.142674

7. Sang-Hun, O., Jung, N., Seog-Ou, Ch., Dong-Hee, L. (2011). A study on the fabrication of a large hollow ingot by CAE. 18th International forgemasters meeting, 12-15 September 2011. Pittsburgh, 179-182.

8. Ohashi, N., Enami, T., Wanaka, H., Aso, K. (1984). Manufacturing process and properties of nuclear RPV shell ring forged from hollow ingot. Nuclear Engineering and Design, 81 (2), 193-205. doi: https://doi.org/10.1016/0029-5493(84)90007-4

9. Machovčák, P., Opler, A., Carbol, Z. et. al. (2013). The development of hollow ingot casting technology at Vítkovice Heavy Machinery A.S. Metal: 22nd International Conference on Metallurgy and Materials. Brno.

10. Jha, A. K., Sreekumar, K., Tharian, T., Sinha, P. P. (2010). Process optimization for high fracture toughness of maraging steel rings formed by mandrel forging. Journal of Manufacturing Processes, 12 (1), 38-44. doi: https://doi.org/10.1016/ j.jmapro.2010.01.007

11. Bao-zhong Wang, Kai-quan, L., Ying, L., Wen-hui, Z., De-li Zhao. (2014). Development of Mono-bloc Forging for CAP1400 Reactor Pressure Vessel. Energy Materials 2014, 443-450. doi: https://doi.org/10.1007/978-3-319-48765-6_52

12. Wang, B. (2017). Development of mono-bloc nozzle shell for CAP1400 RPV. Book of Abstracts: 20th International forgemasters meeting. Graz, 52 .

13. Tanaka, Y. (2015). Reactor pressure vessel (RPV) components: processing and properties. Irradiation Embrittlement of Reactor Pressure Vessels (RPVs) in Nuclear Power Plants, 26-43. doi: https://doi.org/10.1533/9780857096470.1.26

14. Berger, T., Murai, E., Kurihara, I., Nakamura, T., Sasaki, T., Yoshida, T., Koyama, Y. (2007). High intensity forging for nuclear applications: Manufacturing and properties of nozzle shell with integral flange for EPR reactor pressure vessel. Ironmaking \& Steelmaking, 34 (3), 205-210. doi: https://doi.org/10.1179/174328107x174717

15. Nie, S. M., Yu, Z. Q., Meng, D. N., Qi, R. S., Liu, X. G., Jin, M. (2013). Research on Key Processing Technology of Nuclear Power Tapered Cylinder Forging. Advanced Materials Research, 690-693, 2387-2392. doi: https://doi.org/10.4028/www.scientific.net/ amr.690-693.2387

16. Sun, M., Hao, L., Li, S., Li, D., Li, Y. (2011). Modeling flow stress constitutive behavior of SA508-3 steel for nuclear reactor pressure vessels. Journal of Nuclear Materials, 418 (1-3), 269-280. doi: https://doi.org/10.1016/j.jnucmat.2011.07.011

17. Suzuki, K., Sato, I., Kusuhashi, M., Tsukada, H. (2000). Current steel forgings and their properties for steam generator of nuclear power plant. Nuclear Engineering and Design, 198 (1-2), 15-23. doi: https://doi.org/10.1016/s0029-5493(99)00273-3

18. Cleaver, C., Allwood, J. (2017). Incremental profile ring rolling with axial and circumferential constraints. CIRP Annals, 66 (1), 285-288. doi: https://doi.org/10.1016/j.cirp.2017.04.114 
19. Kermanpur, A., Eskandari, M., Purmohamad, H., Soltani, M. A., Shateri, R. (2010). Influence of mould design on the solidification of heavy forging ingots of low alloy steels by numerical simulation. Materials \& Design, 31 (3), 1096-1104. doi: https:// doi.org/10.1016/j.matdes.2009.09.045

20. Khoury, I., Giraud-Moreau, L., Lafon, P., Labergére, C. (2006). Towards an optimisation of forging processes using geometric parameters. Journal of Materials Processing Technology, 177 (1-3), 224-227. doi: https://doi.org/10.1016/j.jmatprotec.2006.04.081

21. Kakimoto, H., Arikawa, T., Takahashi, Y., Tanaka, T., Imaida, Y. (2010). Development of forging process design to close internal voids. Journal of Materials Processing Technology, 210 (3), 415-422. doi: https://doi.org/10.1016/j.jmatprotec.2009.09.022

22. Suzuki, K., Sato, I., Tsukada, H. (1994). Manufacturing and material properties of ultralarge size forgings for advanced BWRPV. Nuclear Engineering and Design, 151 (2-3), 513-522. doi: https://doi.org/10.1016/0029-5493(94)90192-9

23. Chen, K., Yang, Y., Shao, G., Liu, K. (2012). Strain function analysis method for void closure in the forging process of the large-sized steel ingot. Computational Materials Science, 51 (1), 72-77. doi: https://doi.org/10.1016/j.commatsci.2011.07.011

24. Banaszek, G., Stefanik, A. (2006). Theoretical and laboratory modelling of the closure of metallurgical defects during forming of a forging. Journal of Materials Processing Technology, 177 (1-3), 238-242. doi: https://doi.org/10.1016/j.jmatprotec.2006.04.023

25. Bocquet, P., Blondeau, R., Poitrault, I., Badeau, J. P., Dumont, R. (1991). Improvement in the reliability of shells for light water reactors by manufacture from hollow ingots. Nuclear Engineering and Design, 130 (3), 467-475. doi: https://doi.org/10.1016/ 0029-5493(91)90237-c

26. Raz, K., Vaclav, K. (2014). Using of a Hydraulic Press in Production and Manufacturing of Large Rings. Procedia Engineering, 69, 1064-1069. doi: https://doi.org/10.1016/j.proeng.2014.03.091

27. Onodera, S., Kawaguchi, S., Tsukada, H., Moritani, H., Suzuki, K., Sato, I. (1985). Manufacturing of ultra-large diameter $20 \mathrm{MnMoNi} 55$ steel forgings for reactor pressure vessels and their properties. Nuclear Engineering and Design, 84 (2), 261-272. doi: https://doi.org/10.1016/0029-5493(85)90196-7

28. Markov, O. E., Perig, A. V., Zlygoriev, V. N., Markova, M. A., Kosilov, M. S. (2017). Development of forging processes using intermediate workpiece profiling before drawing: research into strained state. Journal of the Brazilian Society of Mechanical Sciences and Engineering, 39 (11), 4649-4665. doi: https://doi.org/10.1007/s40430-017-0812-y

29. Markov, O. E., Perig, A. V., Zlygoriev, V. N., Markova, M. A., Grin, A. G. (2016). A new process for forging shafts with convex dies. Research into the stressed state. The International Journal of Advanced Manufacturing Technology, 90 (1-4), 801-818. doi: https:// doi.org/10.1007/s00170-016-9378-6 